Mid-American Review of Sociology

Karier, Clarence J., Paul Violas and Joel Spring 1973 Roots of Crisis: American Education in the Twentieth Century.
Chicago: Rand McNally. Karmel, Louis J. 1970 Measurement and Evaluation in the Schools. London: The
MacMillan Co. Katz, Michael

1968 T

Mid-Nine Harvard Univerh Century Massachusetts. Cambridge, Mass.

Lauter, Paul and Archibald Alexanc

1969 "ACE: Defender of the Educational Faith." The Antioch Review, (Fall):287-303.

Lazerson, Marvin 1971 Origins of the Urban School: Public Education in Massachusetts, Otto, David

1973 "Pass-Fail Grading Systems: A Literature Review." Albert University, Edmonton. Office of Institutional Research and Planning. (Sept.).

Riesman, David, Joseph Gusfield and Zelda Gamson

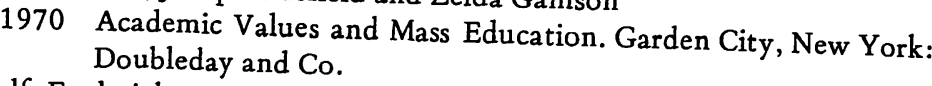

Rudolf, Frederick

1962 The American College and University. New York: Alfred A.

1972 "Organizing the Meritocracy: A History of the College Entrance Examination Board." Harvard Educational Review, (Feb.):34-

Spring, Joel $\mathrm{H}$.

1972 Education and the Rise of the Corporate State. Boston: Beacon Press.

Starch, Daniel, and E.C. Elliott

1912 "Reliability of Grading High School Work in English." School Review, Vol. 20:676-681.

1913 "Reliability of Grading Mathematics." School Review, Vol $21: 445-457$.

Weber, Max

1946 Essays in Sociology, (Trans. Hans H. Gerth and C. Wright Mills)
New York: Oxford University Press.

\section{CLINICAL SOCIOLOGY: PROBLEMS AND PROSPECTS}

\author{
L. Alex Swan \\ Texas Southern University
}

The notion that sociology and sociologists can be "clinical" is beginning to take roots, even though the roots are not well established in the field of "mental health" and other fields having to do with therapy and change. Other clinical professionals do not question the argument that sociology has knowledge and information that can be applied to problems affecting the individual, group, organization, industry and the community. Neither is there any question regarding sociological methods and techniques for producing information and creating knowledge about group life. However, there are various questions being raised by established clinical professionals regarding the "clinical" and "therapeutic" potential and skills of sociologists and sociology. An examination of the clinical nature of psychiatry, clinical psychology, and psychiatric or clinical social work is presented in this paper, and four brief examples are used to demonstrate the clinical nature of sociology.

\section{PROBLEMS}

Sociology is the study of group life, and clinical sociology focuses its attention on groups, although the clinical sociologist may work with individual members of the group as well. Therefore, within the sociocultural context of the group experience, both the micro and macro levels of clinical sociology application can be established.

The social world created by human beings in various social groups and different organizations and social systems suggest that all human problems result from the participation of individuals in group life, and are to a large extent social in nature. Consequently, "problems which appear to be psychological are often the result of difficulties a person has within groups..." (Glassner and Freedman, 1979:287-288). It is because of this understanding that the clinical nature of sociology must be classified and established, and the therapeutic content and techniques of sociologists must be documented and verified. 
It is important to point out that the improvement of the human condition is not the exclusive domain of any one discipline or one group of professionals. Different professions have different ways of understanding and coping with human problems and conditions. It has long been recognized that human beings are multifaceted, and that a one-dimensional approach to understanding and reducing human misery would fail. Human beings and their behavior are best fully understood and influenced by diverse disciplines and professions. One of the problems that sociology and sociologists face in an attempt at being clinical is that as an academic discipline, a clinical branch was never established within the discipline as was the case with the discipline of psychology, and that social work as a profession and social workers as professionals leaned on psychological skills and techniques as they applied sociological knowledge and information to problems of individuals and groups for the purpose of change.

Professionals trained in sociology have to obtain additional training in psychology and clinical supervision if they are interested in settings in which clinicians work, and in the activities in which they engage. This is the case because clinical psychology and psychiatry dominate the clinical content of professional activities that are clinical in nature. Some sociologists have conceded that sociology cannot be clinical in the same way that psychology and psychiatry are clinical, and have defined the involvement of clinical sociologists in clinical settings in terms of research, raising socio-cultural questions and other such roles which tend to render sociology and clinical sociologists secondary in clinical and therapeutic activities. There are several sociologists who have doctorates both in sociology and psychology, or who have doctorates in sociology and have obtained master's degrees in psychology in order to become "legitimate" clinicians. This situation must change if clinical sociologists are to assume primary roles as clinicians in the therapeutic community.

\section{OTHER CLINICIAN PROFESSIONS}

Before we examine the clinical nature of sociology, we will examine the clinical nature of psychiatric social work, clinical psychology and psychiatry that have, over the years, attempted to deal with the mental health problems of individuals. These professions have certain unique features, but they all converge in their focus on mental health. The task of clinical sociology, therefore, is to establish those characteristics that give clinical sociologists their unique identity in clinical activities with other change agents. This task will become increasingly difficult as community psychology establishes itself within the discipline of psychology which views human problems as largely determined by social-community conditions and forces, and seeks to alter these forces and conditions to enhance and upgrade the quality of life and the human situation. Presently, for a variety of reasons, clinical sociology does not have the full support of established sociology as is the case with community psychology and was the case with clinical psychology within the discipline of psychology.

\section{PSYCHIATRISTS AND PSYCHIATRY}

Psychiatrists are trained as physicians, and the discipline of psychiatry is grounded in organized medicine. Consequently, psychiatry and psychiatrists enjoy the status, influence, and professional respectability that the medical profession enjoys. However, psychiatry and psychiatrists rely upon and apply psychological and psychoanalytic thinking and information created primarily by Freud, Jung and Adler, to mental health problems. Although these men were trained in the medical tradition, their contributions were psychological and psychoanalytic in nature and not medical. Today, psychiatrists function in many ways as physicians. For example, they give physical examinations and prescribe medication such as drugs in the treatment of psychological and social difficulties of their patients. Psychipsychological and from the medical tradition with its psychiatric atrists also benefit from the medical tradition with its as suffering from some kind of disease, and can be identified from their from some kind of disease, and can be identification such as paranoia, schizophrenia, hysteria, etc. Not all psychiatrists embrace the 
psychological orientation. There are those who stress the biological, neurological, or genetic factors in explaining mental illness, and recently there are some who have embraced a social orientation in explaining individual failure in adjustment.

Psychiatrists are recognized as experts in the diagnosis of mental illness and have been able to capture the power and influence of being the primary professional in clinical matters of the individual in mental health institutions and agencies assisting individuals manage their lives. This position of a superior role in the mental health professional hierarchy is related primarily to their medical training and background. Secondarily, it is related to the brief training they receive in a psychoanalytic system of thought and psychological orientation within the framework of the supervised training in psychiatry in an outpatient hospital setting. In the American Psychologist, Kiesler (1977) notes that, "psychiatrists receive standard medical training, little formal training in the study of human behavior, and practically no experience in research."

\section{CLINICAL PSYCHOLOGY AND PSYCHOLOGISTS}

Clinical psychology and clinical psychologists are primarily concerned with applying psychological principles and thought to the problems of adjustment and coping of human beings. Like psychiatrists, clinical psychologists are heavily engaged in individual and group psychotherapy, and operate, for the most part, within the framework of a private practice. Unilike the psychiatrist, clinical psychologists do not -prescribe medication. However, a few clinical psychologists are making clinical contributions by generating knowledge for application through research. It is evident that the field is becoming rather complex (Garfield and Kurtz, 1976).

Clinical psychologists have come to establish themselves as experts who could help with a wide range of interpersonal and social problems. Neurosis, psychosis, juvenile delinquency, sexual difficulties, addiction and the like have all gained the attention of clinical psychologists.
The clinical nature of clinical psychology has to do with its ability to make assessment of human potential, and test or measure human abilities, skills, mental dispositions, personality functioning, and mental dysfunction and disorders. It is believed that it is only through the testing and assessing of the individual's personality can we provide an understanding of the person's difficulty. This assessment leads the clinician to determine the psychotherapeutic techniques and behavior therapy capable of effectively and satisfactorily dealing with the individual's problem and altering the behavior.

In spite of the clinical psychologist theoretical orientation and persuasion, personality testing and assessment is an important and vital step in clinical diagnosis and treatment. This is considered the best approach because it allows them to feel confident in the selection of an appropriate therapeutic procedure. For a number of reasons however, in recent years, the role of diagnosis as a crucial step in clinical matters has declined somewhat (Lewandowski and Saccazzo, 1976).

Although there is some research conducted by clinical psychologists, it is felt that this activity must increase if evaluation is to be made of the effectiveness of their own clinical activities. Because external agencies and regulatory bodies have the power to sanction these clinicians, they are willing to include sociologists carrying various labels as consultants and researchers, to perform the research task.

Aside from the validity of the psychological tests and personality assessments, the magic and mystique of clinical psychologists are associated with their use of these tests which have increased their professional acceptance and provided recognition and identity in the mental health profession. Clinical sociologists have no such identity and recognition, and have not established a basis for a clear and distinct identity among mental health professionals.

\section{THE PSYCHIATRIC SOCIAL WORKER}

The psychiatric social worker as well as the clinical psychologist and the psychiatrist are becoming increasingly absorbed 


\section{Mid-American Review of Sociology}

by the practice of psychotherapy. The psychiatric social worker conducts psychotherapy on an individual or group basis and is also involved in the process of diagnosis. Traditionally, the social worker focused upon the social forces and the external agents that account for the difficulties of the patient. Interviews, case histories, counseling, and vocational placement have been the special tasks of the psychiatric social worker, while the clinical psychologist performed the test and the psychiatrist conducted the psychotherapy. Over the years, there developed a close relationship among these clinicians which resulted in the social worker putting more emphasis on intrapsychic forces than on social and external forces in the determination of their clients' pathology. With the embracing of systems theory, social workers, in very recent years, are returning to their prior focus on familial and social determinants of the difficulties and problems faced by individuals.

One of the special characteristics of social workers has been their intense involvement with their patients everyday lives and problems. Their home visits, or visits to the places where their clients spent the bulk of their time identified their unique approach to clinical diagnosis and treatment. In private practice they operate much like the clinical psychologist and the psychiatrists, and as a member of a team of clinicians in hospitals, social service agencies, and mental health clinics, the emphasis on the social and external factors distinguishes their
input and tasks.

\section{THE PROSPECT OF SOCIOLOGY-BEING CLINICAI}

Given the established activities of the above clinicians, what is there for clinical sociologists to be clinical about? Is it necessary and sufficient to receive academic training in sociology at the graduate level and then intern under the supervision of clinical psychologists and psychiatrists to become legitimate clinicians? With the number of people needing help increasing, and the growing need for many sociologists to become clinicians, can clinical sociologists cut out a distinct role and an identity among other clinicians without threatening their identity and
Problems and Prospects

reducing their power and influence in clinical matters? Is sociology sufficiently allied to settings that employ clinical psychologists, psychiatrists and psychiatric social workers to enter the holy trinity of mental health.

To adequately answer these questions, we must first answer two questions: What can sociology do and, of what use is sociology in clinical matters? (Swan, 1980). Most clinicians admit that sociology has produced valuable knowledge and thinking that they and other professionals use in the therapeutic community. Clinical sociologists must go beyond the roles of providing clinical research information, offering sociological insights and analysis as consultants, social analysts and raising the sociocultural questions, to combining these roles and applying the knowledge and information themselves to problems faced by groups, individuals in group life, communities and organizations.

Human behavior emerges within a social context, and its occurrence results from a reality created by the individual through the process of interpretation. The social context or the social situation must be diagnosed along with the reality created through the process of interpretation if sociologists are to become clinical. This is the perspective clinical sociologists bring to clinical matters of group life. The successful treatment of any problem, and the effective application of knowledge and thinking to problems must be rooted and grounded in the diagnosis of the situation content. In many cases, clinicians deal with problems without a clear understanding or appreciation for the social situation/context out of which the behavior emerged. Neither are they always fully aware of the definitions, interpretations and meanings brought to the situation or imposed upon the situation by individual participants.

The potential for clinical sociologists to become clinical is related to and depended upon the extent to which their diagnosis of problems is grounded and rooted in the social situation/context of the behavior-to include definitions, meanings and interpretations. To execute this clinical orientation, clinical sociologists must develop diagnostic procedures that are reliable, valid, verifiable and effective: that is, they are able to produce answers for appropriate action. Assessment of the 
situation and the interpretations facilitate the judgment process, and the diagnosis is combined with therapy to bring about change. In other words, one is not a clinician merely because he is qualified in the clinical practice of medicine, psychiatry or psychology, or because one is specialized in laboratory and research techniques. Being clinical is not merely related to conduct in a clinic. The sociologist is a clinician or is clinical when she is involved in direct observation, assessment and measurement of a social situation, process and pattern of interaction in the group which can be discerned by the professional eye providing insight based upon his knowledge of the subject matter. This observation, measurement, and assessment must be for the purpose of diagnosis and treatment of the (sick) situation or pattern of interaction. The situation is a group situation, and not an individual situation, and the focus is not on emotional disturbance but rather on interpersonal behavior and human relations skills in group situations and intergroup relations.

\section{THE CLINICAL NATURE OF CLINICAL SOCIOLOGY}

Four examples will be presented to indicate the clinical nature of clinical sociology, and the precise role clinical sociologists can play in changing social situations to produce growing, developing, and productive relations between and among individuals in group life.

All four examples require diagnosis which is the determination of the basis and nature of the abnormality of the situation and/or the pattern of interaction. Any procedure that is utilized in an effort to determine the nature and source of situational or interactional abnormality is a diagnostic test and would enhance the probable cause of the disorder, its treatment and prognosis.

The goal of the clinical sociologist is the resolution of intergroup and intragroup strains and conflicts that interfere with the attainment of various group ends. This may require the redefinition of certain situations and/or the restructuring of certain social situations. The clinical sociologist bears in mind that the situation can take on the significance that individuals in group life give it, and that social reality is often created by assessing and interpreting the actions and expectations of others in group life. W.I. Thomas has pointed out that; "if men define situations as real they are real in their consequences" (Thomas, 1961). While psychological interpretations might be required for individual coping with problems and conflicts, sociological interpretations are required to change the situation and patterns of interaction in the social situation of the group. Often, "psychological interpretation tends to ignore the impact of the situation upon individuals; and the participation of individuals in collective processes in which affects beliefs, values, and aims are shared, often unwittingly" (Edelson, 1970).

\section{Example I}

One of the most pressing problems that confront community members is crime and the fear of crime. Communities have left the situation of crime and its solution to law enforcement officials and other criminal justice subsystems with little or no success or progress. This failure can be explained in a number of ways. However, clinical sociologists can address the situation of crime in the community to reduce and eliminate the fear of crime by community members without the necessity of employing a psychological orientation to develop coping skills of such members.

In many urban communities the fear of crime and the increasing likelihood of victimization have caused community members to alter their lifestyles in order to deal with increasing criminal activity. After a comprehensive study of one community, a clinical sociologist made the following observation: The community members felt helpless in establishing protection against criminal activity in their community; the response time of the police was too long, members felt that the police lacked functional knowledge of the community; there was a sense that the perpetrators of crime in the community perceived the community as powerless and helpless in dealing effectively with the situation of crime; the members felt that the perceptions of the police of the community and the nature of 
policing deterred the reduction and elimination of criminal activity in the community. Even though apprehension was high, it came too late after the commission of the crimes and did very little to reduce the fear in the community.

The clinical sociologist concluded that the situation of crime in the community, the context of which was the basis for the fear had to be changed by first redefining or changing the philosophy of policing from apprehension, which requires the commission of a crime, to the prevention of the occurrence of crimes. This change could occur only by establishing a structure in the community out of which policing would be done. The benefits were identified as: 1) having police protection close to and as a part of the basic service to the community; 2) a reduction of the response time; 3 ) the training of many of the community youth as parapolicemen; 4) reducing the afterthe-fact nature of the police presence and policing; 5) maximizing police-community interaction and relations, and 6) restoring a sense of community to the police who live and work in the community and to the members of the community.

The Area Agency that was recommended as the community mechanism for dealing with the situation of crime in the community, and the fear of its members, incorporated the ability to deliver two umbrella functions: 1) protection to the community members and their property, and 2) prevention of the occurrence and continuation of crime. It was also recommended that this Area Agency would be accountable to a Supervisory Board, the composition of which would reflect the various characteristics of the community. The details of the Community Area Agency, and the specific functions and powers of the Supervisory Board were to be worked out with representatives of various organizations in the community and the downtown police department, in consultation with the clinical sociologist.

The attempt and focus of the clinical sociologist in this example was to treat the situation of crime out of which community fears emerged. Dealing with the members fears above without addressing the situation was thought to be useless and secondary to the problem of crime in the community. Developing an ability to cope with fear did not remove the situation of fear; the presence and function of the Community Area Agency did.

\section{Example II}

A new minister was employed to pastor a congregation of about six hunderd members. The church had had a positive relationship with its previous pastors who were defined by the members as dynamic persons. It was very evident that the pastors had left their impact on the congregation and that the church was pastor-oriented. Even though there was a leadership structure established in the church, the congregation depended on the pastor for leadership with input from them. The approach of the new pastor in managing and planning for the church did not involve the traditional leaders of the congregation or any other group of members. He had his own ideas and plans and did not accept nor invite much input. He also took little or no time to understand the situation or listen to those who knew the situation. The pastor was in his fifties and had pastored several churches across the nation. Consequently, his tendency was to suggest and employ techniques, programs and policies that were employed by him elsewhere insisting that they should work in this new situation. For several months there was a measure of financial success based on appeals to the members stewardship commitments to the financial obligations of the church. However, there was a severe case of alienation and feelings of rejection floating around in the congregation. This resulted in fragmentation of the congregation; a falling away of members, and negative conversations about the pastor's ability to manage the affairs of the church. The problem was recognized by the pastor but defined as a spiritual problem which was individual in nature and had to be solved individually.

After interviewing a cross section of the members, in cluding members of the Church Board, it was evident to the clinical sociologist that they felt alienated and distant in their relationship with the pastor. They felt their definitions of the problems were different and that the pastor had not taken the time necessary to fully understand the dynamics of the church. 
There existed also in the church a number of followings with leaders, official and self-appointed, who were persuasive enough to keep their followers loyal to their influences. This situation had to be changed if the congregation were to grow, numerically and spiritually, and if the pastor was to be a successful leader managing the affairs of the congregation and planning and initiating programs.

The pastor was convinced by the clinical sociologist that the situation had to be changed if he intended to save the church as a congregation of people, and not the church building, from total collapse.

A series of steps were recommended by. the clinician which included: 1) an open meeting with the church to hear what members had to say about the problems of the church, and their recommendations for dealing with the problems. It was important to remind the pastor that the session was primarily an information gathering session and a period for the members to be heard. Consequently, he did not have to be defensive in his responses and disposition during the session. If one such session was not sufficient time for this experience, it was agreed that other sessions should be planned, and 2) that small group sessions be planned to work out feelings and deal with interpersonal relationships within the church. The composition and focus of the groups were determined initially by the clinical sociologist and they were given specific tasks. The fellowship hall was used to accommodate the groups, and the clinical sociologist moved from one group then another making observations. Sociograms and role taking were used in the groups, and the persons chosen to represent their groups before the entire membership, reported on what went on in their groups. Feedback was given, and questions were raised, and the clinical sociologist assisted in the exchange providing insights in group processes and the particular dynamics operating in their situation.

As a result of these experiences, the pastor was assisted in receiving the information and insight he needed, and the congregation developed a sense of being involved in the affairs of the church, and there was evident reciprocity in the relationships of the pastor and the members. The congregation is slowly experiencing growth.

\section{Example III}

A couple that came to the attention of a clinical sociologist at a university, requested a marital check-up which was to be conducted in the clinical office. During the third session it became apparent that they were having problems with their finances. In fact, they began arguing about the matter and accusing each other until the clinician had heard enough to intervene.

The husband had two jobs which paid significantly different amounts and the wife took the responsibility to manage the income and expenditures. After a number of questions by the clinician, he asked the wife if she had a budget. "A budget?" she asked in somewhat of an astonishment.

"Yes, a budget for managing your income and expenditures?" She did not have a budget and it was very evident that the husband was not involved in the management. The couple was asked to put on paper their entire income and expenditures and to return for their fourth session which would consist of establishing a functional budget. Before the beginning of the planning of the budget, the couple talked about the quarrels and almost physical fights over their financial situation. The clinical sociologist then explained the importance of a budget in management of money and what would happen to their financial and marital situation when the budget plan is adopted and carefully followed. The clinician further explained the various sections of the budget and how certain items can be manipulated to facilitate their various and changing interest, needs and wants from month to month. They were amazed that it was possible to have a little income left and wondered where it came from. They were also happy to be able to look at one sheet of paper and view their entire financial situation for each month. Also included on the budget was provision for a specified amount for saving. The husband was encouraged to participate in the planning of the budget each month. There are cases, however, when the quarreling over financial matters has 
caused damage to the couple's interpersonal relations and as a result, gains independence as a problem apart from the financial situation. Sometimes the quarreling would shift to other situations which must be addressed if growth and development are to be achieved.

The establishment of a budget-a mechanism for managing their financial obligations-changed their financial situation, and changed their discussion of the need of the wife to find employment, who was complaining of two physical ailments.

The relief resulting from the placement of a budget in the family life of this couple was evident and the marital check-up went on to completion.

\section{Example IV}

A significant number of people perceive work as a source of satisfaction and reward. Tranquility on the job is often sought and found, and many career-minded persons would often leave home and head toward their offices searching for a tranquil experience. There is no doubt that the world of work offers such potential reward and satisfaction. However, the experience of many in the world of work is that the job situation can produce stress which is harmful and disturbing in its affect on the individual and the growth and development of the group. Actually, only a few people can and will avoid job stress in the work environment. In working with job-related stress, the clinical sociologist must first identify the sources of stress in the particular world of work.

Stress may be understood to be an internal reaction to an outside stressor. However, the understanding appropriate to the world of work is external and/or internal forces which create pressures on individuals. An example of this would be work demands that are considered unreasonable.

The first concern of the clinical sociologist was to determine the conditions wherein the job-related factors were interacting with the workers to change their physiological, psychological and sociological state which caused them to deviate from their adequate and productive functioning. The clinical sociologist became a participant-observer and concluded that there were three organizational sources of stress that workers faced.
The first discovered was exorbitant work demands, next was confusing directions and conflicting demands, and in several cases there was evidence of an underutilization of workers abilities. The clinician determined that the job-related stress had affected a few workers and that it was necessary to recommend that they learn how to relax and meditate. Further, there was evidence that they needed to improve their work habits. Beyond the individual methods suggested for reducing and preventing job-related stress, the clinical sociologist recommended and assisted in improving the organizational climate, making it supportive and getting the organization to visibly demonstrate its concern for the welfare of the workers. Several employees voiced the opinion that the organization disregarded their feelings and wishes and because of this they were dissatisfied and in turn had no real concern for the quantity and quality of their production. After convincing management of its worth, the clinician organized stress release activities which included meditation, and exercise, and counseling sessions in rooms established for such purposes. There was also a room designated "hostility room" where employees could rid themselves of stored-up hostility by punching bags and inflatable figures which represented or were symbols of offending persons (Albrecht, 1979). In order to deal with the feelings of being left out of important decisions that affected their welfare, the clinician established a system for informing the employees of important issues and for receiving and processing their decisions. Management made a commitment to the participative decision making program and assured the employees that their input would be given much weight. This commitment and process gave workers a sense that they had a degree of control over the condition surrounding their work situation.

The clinical sociologist continued to monitor the work environment to insure that the sources of organizational stress were controlled and managed. Since work is an important source of reward and satisfaction, and in some cases a more dominant source than their home or church, it should be of continued significance to the lives of workers-employees and managersthat sources of stress, both organizational and individual be 
identified and managed. The results will be improved and increased job performance; job satisfaction, job security, etc.

\section{CONCLUSION}

There are a number of ways and areas in which clinical sociologists can demonstrate their abilities and skills in being clinical without actually threatening the roles of established clinicians. This is the case for several reasons; however, the most important is that sociology is the study of group life and human interaction, and clinical sociologists, trained in sociological theory and methods, can apply sociological thinking and knowledge to the problems of groups as they seek to change situations and conditions out of which these problems and difficulties emerge. There is therefore, a legitimate role for clinical sociologists at the micro as well as the macro levels in the therapeutic community as change agents. Consequently, sociologists should not seek to practice psychotherapy when they can establish their worth and importance as sociotherapists practicing sociotherapy (Edelson, 1970).

Clinical sociologists, in being clinical, must engage themselves in a methodological and theoretical approach that is based upon situation analysis aimed at attaining a critical view of social reality by locating the concrete social situation out of which problems emerge. This approach (Grounded Therapy), includes the definitions, interpretations, and meanings of those implicated in the social situation. Diagnosis, therapeutic intervention and strategies for change are developed out of the process of the situation analysis.

No doubt there will be continued debates between and among clinicians regarding the role of the clinical sociologist, and the ability of sociologists to be clinical. Sociology has produced the knowledge and skills for clinical sociologists to apply, and there are those who are working at various levels with various groups changing situations, improving conditions and bringing satisfaction and rewards to individuals in group life. A good number of these sociologists have not felt the need to be legitimized by the traditional clinicians who now dominate the field. To do so could very well be a mistake in the attempt to establish the practice of clinical sociology and the field as an important addition or distinction to what is presently available.

\section{REFERENCES}

Albrecht, Karl

1979 Stress and the Manager: Making It Work For You. Englewood Cliffs, N.J.: Prentice-Hall.

Edelson, Marshall

1970 Sociotherapy and Psychotherapy. Chicago: University of Chicago Press.

1970 The Practice of Sociotherapy. New Haven, Conn.: Yale University Press.

Garfield, S.L. and R. Kurtz

1976 "Clinical Psychologists in the 1970's," American Psychologist 31:1-9.

Glassner, Barry and Jonathan Freedman

1979 Clinical Sociology. New York: Longman.

Kiesler, C.A.

1977 "Editorial: The Training of Psychiatrists and Psychologists," American Psychologist 32:107-108.

Lewandowski, D.G. and D.P. Saccazzo

1976 "The Decline of Psychologisting Testing," Professional Psychology 7:177-184.

Swan, L. Alex

1980 "Clinical Sociologists: Coming Out of the Closet," Mid-Americn Review of Sociology 1 (Spring):89-98.

Thomas, W.I.

1961 "The Four Wishes and the Definition of the Situation," pp. 741746 in T. Parsons et al. (eds.) Theories of Society. New York: Glencoe, Free Press. 